\title{
CASCA DE MACADÂMICA COMO BIOADSORVENTE PARA ÓLEOS E GRAXAS
}

\author{
F. B. NETO ${ }^{1 *}$, G. G. M. RODRIGUES ${ }^{1}$, A.G. KISTER ${ }^{1}$, A.S.ALMAGRO ${ }^{1}$; E.R.NUCCI ${ }^{2}$, \\ S.M.S.ROCHA ${ }^{3}$
}

${ }^{1}$ Universidade Federal do Espírito Santo, Departamento de Engenharias e Tecnologia ${ }^{2}$ Universidade Federal de São João Del Rei, Departamento de Química, Biotecnologia e Engenharia de Bioprocessos

${ }^{3}$ Universidade Federal do Espírito Santo, Departamento de Educação e Ciências Humanas *e-mail: fernandob_155@hotmail.com; sandra.m.rocha@ufes.br

\begin{abstract}
RESUMO
A Revolução Industrial trouxe consequências imprevisíveis ao meio ambiente o que provocou uma pressão nas indústrias pela busca da produção sustentável. Dentre os impactos gerados, a degradação dos recursos hídricos passou a ocupar um lugar de destaque frente à legislação Ambiental. Neste panorama os efluentes oleosos merecem atenção, visto que além de apresentar todos os problemas dos demais efluentes, se a porção de óleos e graxas não for eliminada poderá formar um filme na superfície dos corpos hídricos inibindo a troca de oxigênio com o ar, bem como a penetração da luz solar, impossibilitando a realização de fotossíntese, diminuindo assim o oxigênio dissolvi no corpo d'água. Os efluentes oleosos são gerados nas mais diferentes indústrias, tanto naquelas que usam o óleo ou oleaginosas como matéria-prima, como em oficinas mecânicas, postos de gasolina, equipamentos movidos a óleo hidráulico, e manutenção de mecânica pesada. Todos os efluentes industriais devem ser tratados de forma que se enquadrem nos limites estabelecidos pela legislação ambiental, antes do seu descarte. Neste contexto esse trabalho analisou a técnica de adsorção com casca da macadâmia para o tratamento de efluentes oleosos. Para isso determinou-se as condições ótimas de adsorção do óleo pela casca macadâmia, como $\mathrm{pH}$, cinética de adsorção, concentração e granulometria do bioadsorvente. Concluindo que a casca de macadâmia pode ser utilizada com adsorvente para óleos e graxas.
\end{abstract}

\section{INTRODUÇÃO}

A Revolução Industrial trouxe, juntamente com um crescimento tecnológico e desenvolvimento econômico, consequências imprevisíveis ao meio ambiente. Durante décadas os impactos ambientais gerados pela industrialização não receberam a atenção necessária, elevando estes problemas à nível global. Com a busca desenfreada pelo desenvolvimento, concomitante ao crescimento populacional, os impactos ambientais tomaram proporções inimagináveis até mesmo para a ciência. Devido à estas proporções, juntamente com a consciência ambiental dos consumidores advinda dos movimentos ambientalistas, as indústrias se viram pressionadas a atingir $\mathrm{o}$ 
desenvolvimento econômico e suprir as necessidades de uma população, superior a 7 bilhões de pessoas, sem degradar o ambiente, iniciando a era do desenvolvimento sustentável.

A busca pela produção sustentável, exigido tanto pelo mercado nacional como o internacional, fez com que as empresas investissem em tratamentos de resíduos sólidos, líquido e gasosos, criando assim, um novo mercado: o de equipamentos para controle ambiental. Dentre os impactos ambientais gerados pela indústria, merece destaque a degradação dos recursos hídricos, visto que as reservas de água doce de qualidade estão cada vez mais distantes dos grandes centros populacionais. Dentre as soluções para preservar e até mesmo recuperar os recursos hídricos tem-se a reconstituição da mata ciliar, preservação de nascentes e o reflorestamento das cabeceiras dos rios. Porém, todos estes esforços seriam perdidos se as indústrias não tratassem seus efluentes, a níveis passíveis de autodepuração do corpo d'água que receberá este efluente, como exigido pela legislação.

A utilização crescente de tecnologia na indústria fez com que aumentasse um dos componentes dos efluentes das mais diversas indústrias; os óleos e graxas, que deixam de ser exclusivos das indústrias que processam óleos ou matérias-primas oleaginosas e passam a compor os efluentes de quase todos os seguimentos industriais devido ao uso de máquinas e automóveis.

Os óleos e graxas componentes de efluentes geram uma poluição visual, além da toxicidade para a fauna e a flora dos corpos receptores. A diferença de densidade dos óleos e graxas em relação à água, faz com que seja formada na superfície do corpo d'água um filme sobrenadante insolúvel que impede a troca de oxigênio da superfície da água com o ar que a circunda, bem como diminui ou até impede a penetração da luz solar, dificultando ou impossibilitando a realização da fotossíntese. Tal fato acarreta na baixa concentração de oxigênio dissolvido no corpo hídrico, podendo eliminar os seres vivos que ali habitam.

As características apresentadas pelos efluentes oleosos mostram que apenas os tratamentos convencionais utilizados nas estações de tratamento de efluentes (ETE) não são eficientes para a eliminação dos óleos e graxas, visto que estas substâncias podem estar presentes nos efluentes na forma de óleo livre, emulsões instáveis e solubilizado.

$\mathrm{O}$ tratamento de efluentes oleosos tem sido um problema enfrentado por diversas indústrias devido à remoção insuficiente da elevada carga orgânica recalcitrante (superior a $50.000 \mathrm{mg} \mathrm{O} \mathrm{O}_{2} . \mathrm{L}^{-1}$ de DQO) em estações de tratamento de efluentes convencionais (SANTOS, 2013). Além deste problema, o aumento da demanda por água em conjunto com as pressões pela minimização do descarte dos efluentes no ambiente, carrearam a investigação e desenvolvimento de técnicas diferentes daquelas clássicas para o tratamento de efluentes, demandando técnicas com baixo custo benefício e que permitam à reutilização tanto da água quanto do óleo separado. Dentre as tecnologias de tratamento mais eficientes para a eliminação de frações oleosas do efluente, consta-se a adsorção, que é uma operação espontânea de transferência de massa do tipo sólido-fluido, na qual se explora a habilidade de certos sólidos em concentrar na sua superfície determinadas substâncias existentes em soluções líquidas ou gasosas, o que permite separá-las dos demais componentes dessas soluções (GOMIDE, 1988).

Adsorção é um fenômeno de superfície no qual um soluto é removido de uma fase fluida e acumulado na superfície de uma fase sólida. O material adsorvido é denominado de adsorbato, e o material, sobre o qual o soluto é depositado, é chamado de adsorvente (RUTHVEN, 1984). 
Quando as moléculas de adsorbato presentes na fase fluida atingem a superfície do adsorvente, a força residual, resultante do desequilíbrio das forças de Van der Waals que agem na superfície da fase sólida, cria um campo de força que atrai e aprisiona a molécula. O tempo que esta molécula de adsorbato fica ligada à superfície do adsorvente depende diretamente da energia com que a molécula é aprisionada, ou seja, depende da relação entre as forças exercidas pela superfície sobre essas moléculas e as forças de campo das outras moléculas vizinhas (RUTHVEN, 1984).

A utilização dos resíduos agroindustriais como adsorventes para a recuperação de efluentes industriais é uma prática viável (POLLARD et al., 1992). Por isso tem crescido o número de pesquisas envolvendo resíduos industriais. Existe um adsorvente de extrema eficiência no mercado, que é o carvão ativado, porém possui custo elevado, inviabilizando a sua aplicação em larga escala. Portanto, as pesquisas visam encontrar um material de baixo custo para ser utilizado como adsorvente em substituição ao carvão ativado. Dentre os resíduos agroindustriais pesquisados, se encontra a macadâmia, que possui elevado teor de material ligno celulósico, que a classifica como um potencial bioadsorvente.

Neste contexto este trabalho visa avaliar a capacidade da casca de macadâmia (MacadamiaintegrifoliaMaid. \& Bet.) in natura na adsorção da fração de óleos e graxas de um efluente oleosos oriundo da caixa de separação água/óleo de um posto de combustível.

\section{MATERIAIS E MÉTODOS}

O efluente utilizado nos experimentos foi um efluente oriundo de uma caixa de separação de água/óleo de um posto de gasolina comercial da região norte do Espírito Santo. Esse efluente foi submetido a tratamentos primários, de forma a eliminar a fração de óleo livre presente.

As cascas de macadâmia foram recolhidas em uma empresa de beneficiamento de noz de macadâmia na região norte capixaba. Estas cascas foram lavadas com água corrente e secas em estufa a $60^{\circ} \mathrm{C}$ por 24 horas. As cascas secas foram trituradas em moinho de facas e lavados com água destilada para aumentar o número de sítios para adsorção. As lavagens foram feitas em um intervalo de $30 \mathrm{~min}$, e na proporção em massa 10:1 (água:adsorvente). As cascas trituradas e limpas foram secas na estufa a $60{ }^{\circ} \mathrm{C}$ durante 24 horas, e então peneiradas para obtenção da granulometria entre $0,600<\mathrm{x}<1,70 \mathrm{~mm}$.

As concentrações de óleos e graxas foram medidas usando o método gravimétrico adaptado do Standard Methods (APHA, 2012). Esse método consiste na extração da fase orgânica da fase aquosa utilizando-se hexano como solvente. As amostras analisadas tiveram seu $\mathrm{pH}$ reduzido para 2 com $\mathrm{H}_{2} \mathrm{SO}_{4}$ visando facilitar a quebra das moléculas oleosas na extração com o hexano. Cada amostra de 25 $\mathrm{mL}$ foi submetida à operação de extração por três vezes com aproximadamente $10 \mathrm{~mL}$ de hexano em funil de separação. A fase oleosa foi levada para estufa a $100{ }^{\circ} \mathrm{C}$ para evaporar o solvente. Após evaporar, o béquer contendo o óleo foi levado para o dessecador e tiveram suas massas pesadas em seguida.

O TOG foi determinado em ppm a partir da Equação:

$T O G=\frac{\left(M_{f}-M_{i}\right) * 1000}{V(L)}$

Em que: $M_{f}$ é a massa final em miligramas do béquer com resíduos, $\mathrm{M}_{\mathrm{i}}$ é a massa do béquer tarado e $\mathrm{V}$ é o volume em litros da amostra.

O percentual de remoção do TOG foi calculado pela equação: 


$$
\% T O G=\frac{\left(T O G_{t=0}-T O G_{t=x}\right)}{T O G_{t=0}}
$$

Sendo: TOG $_{\mathrm{t}=0}$ o Teor de Óleos e Graxas e $\mathrm{TOG}_{\mathrm{t}=\mathrm{x}} \mathrm{o}$ TOG realizado após a adsorção.

Os ensaios de adsorção foram realizados em batelada, a partir da agitação magnética de béqueres contendo $200 \mathrm{~mL}$ de efluente oleoso e $0,2 \mathrm{~g}$ de casca de macadâmia, até o teste de concentração, com o teor de óleos e graxas inicial, determinado. Após a operação de adsorção as análises de TOG foram feitas de forma a se determinar a porcentagem de remoção de óleos e graxas. Todos os ensaios foram realizados em agitadores magnéticos.

$\mathrm{O}$ primeiro teste foi realizado para determinar o $\mathrm{pH}$ ótimo de adsorção. Os pHs testados foram 2, 4, 6, 7, 8, 10, 12. Em cada béquer foi adicionado $200 \mathrm{mg}$ do adsorvente de granulometria 1,180 mm. Após 4 horas de agitação a temperatura ambiente, foram feitos os TOGs para a determinação do pH ótimo.

Após a determinação do $\mathrm{pH}$, foi feito o teste para a cinética de adsorção. Utilizando o pH ótimo, foram testados os tempos de 10, 20, 30, 60, 120 e 240 minutos. Em cada béquer foi adicionado $200 \mathrm{mg}$ do bioadsorvente de granulometria $1,180 \mathrm{~mm}$. O teor de óleos e graxas das amostras após os testes foi determinado para se avaliar o tempo ótimo para a adsorção da fração de óleos e graxas.

Com o pH ótimo e o tempo ótimo já determinados, foram feitos os testes para a influência da concentração de adsorvente na adsorção. As concentrações utilizadas foram de $0,001 \mathrm{~g} / \mathrm{mL} ; 0,002 \mathrm{~g} / \mathrm{mL} ; 0,01 \mathrm{~g} / \mathrm{mL} ; 0,02$ $\mathrm{g} / \mathrm{mL} ; 0,03 \mathrm{~g} / \mathrm{mL}$ e $0,05 \mathrm{~g} / \mathrm{mL}$. O teor de óleos e graxas foi determinado para se avaliar a concentração ótima para a adsorção da fração de óleos e graxas.

Utilizando o pH ótimo, tempo ótimo e concentração ótima, foram feitos os testes para a temperatura. As temperaturas testadas foram à ambiente, $40^{\circ} \mathrm{C}, 50^{\circ} \mathrm{C}, 60^{\circ} \mathrm{C}$ e $70^{\circ} \mathrm{C}$. Após os testes, foram feitos o TOG de cada temperatura a fim de se obter a temperatura ótima.

E utilizando as condições ótimas de $\mathrm{pH}$, tempo, concentração e temperatura, foram feitos os testes para a influência da granulometria do adsorvente na adsorção. As granulometrias usadas foram de $1,700 \mathrm{~mm}$; $1,180 \mathrm{~mm} ; 0,850 \mathrm{~mm} ; 0,710 \mathrm{~mm} ; 0,600 \mathrm{~mm}$ e $<0,600 \mathrm{~mm}$ (fundo). O teor de óleos e graxas foi determinado para se avaliar a granulometria ótima para a adsorção da fração de óleos e graxas.

\section{RESULTADOS E DISCUSSÕES}

As partículas de macadâmia após a trituração e a secagem, foram peneiradas utilizando as peneiras da série Tayler como está apresentado na Tabela 1.

Tabela 1: Peneiras utilizadas na separação das cascas de macadâmia triturada

\begin{tabular}{cc}
\hline Série de peneira (mesh) & $\begin{array}{c}\text { Abertura da peneira } \\
(\mathrm{mm})\end{array}$ \\
\hline 10 & 1,700 \\
14 & 1,180 \\
20 & 0,850 \\
24 & 0,710 \\
28 & 0,600 \\
\hline
\end{tabular}

O mesh 14 foi utilizado nos testes para determinar as condições ótimas, pois obteve a maior porcentagem em massa na peneiração.

Para a realização dos testes preliminares, foi calculado o TOG do efluente bruto utilizado nos testes. O TOG foi feito em triplicata, obtendo um TOG médio (ppm) de 153,33 com desvio médio de 12,86. Esse efluente foi utilizado em todos os testes aqui apresentados.

A primeira condição ótima determinada foi o $\mathrm{pH}$. $\mathrm{O} \mathrm{pH}$ da solução afeta as cargas na superfície dos adsorventes assim como influencia na ionização de solutos, ou seja, interfere nos íons presentes, dificultando ou não a operação de adsorção. Para determinar o pH ótimo, calculou-se o teor de remoção de 
óleo utilizando a equação 1 . Os resultados estão apresentados na Tabela 2.

Tabela 2: Valores dos TOG's e dos TOG's médios para o efluente em diferentes valores de $\mathrm{pH}$.

\begin{tabular}{ccccc}
\hline $\begin{array}{c}\text { pH da } \\
\text { amostra }\end{array}$ & $\begin{array}{c}\text { TOG 1 } \\
(\mathrm{ppm})\end{array}$ & $\begin{array}{c}\text { TOG 2 } \\
(\mathrm{ppm})\end{array}$ & $\begin{array}{c}\text { TOG } \\
\text { Médio } \\
(\mathrm{ppm})\end{array}$ & $\begin{array}{c}\text { Desvio } \\
\text { Padrão }\end{array}$ \\
\hline 2 & $1036^{*}$ & $932^{*}$ & $984^{*}$ & 73,54 \\
4 & $316^{*}$ & 112 & $214^{*}$ & 144,25 \\
6 & $188^{*}$ & $184^{*}$ & $186^{*}$ & 2,83 \\
7 & 96 & 108 & 102 & 8,49 \\
8 & 40 & 52 & 46 & 8,49 \\
10 & 68 & 40 & 54 & 19,80 \\
12 & 20 & 60 & 40 & 28,28 \\
\hline
\end{tabular}

*representa resultados maiores que a do efluente utilizado

Os resultados apresentados pela Tabela 2 mostra que para $\mathrm{pH} \mathrm{2,4,6}$ o TOG médio calculado foi maior que o efluente bruto utilizado. Isso pode ter ocorrido pelo fato do $\mathrm{pH}$ ácido auxiliar a retirada do óleo presente na casca da macadâmia, assim acredita-se que não ocorreu adsorção do óleo pela casca de macadâmia nesta condição e sim extração do óleo presente no material bioadsorvente, visto que o $\mathrm{pH}$ ácido facilita a quebra das moléculas de óleo presentes no material (Figura 1)

Figura 1- Efeito do pH na remoção de óleo do efluente. Resultados para TOG médio.

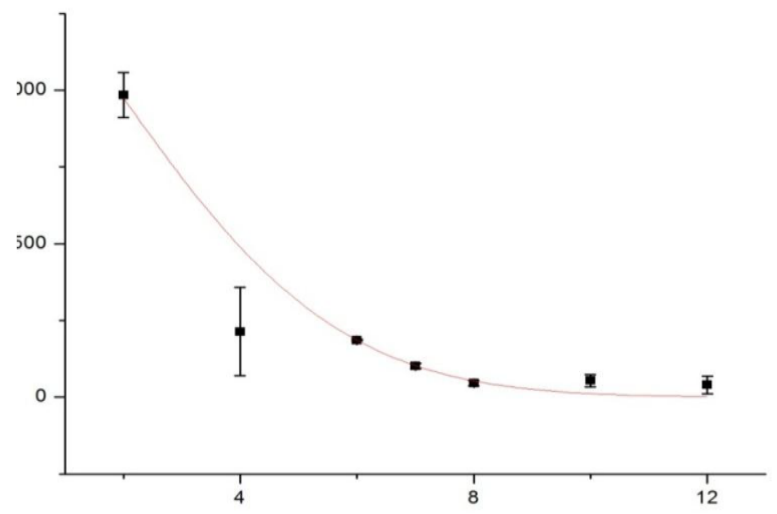

$\mathrm{pH}$

A Figura 1 mostra a variação do TOG com a mudança de $\mathrm{pH}$ do meio, ou seja, mostra a influência do $\mathrm{pH}$ na remoção de óleos e graxas. $\mathrm{O}$ ajuste da curva para os pontos da
Figura 1 obteve um $\mathrm{R}^{2}$ igual a 0,967 , sendo assim, uma aproximação válida para os dados avaliados.

A porcentagem média de remoção de óleos e graxas para cada $\mathrm{pH}$ estudado foi calculado pela Equação 2, (Figura 2).

Figura 2- Porcentagem de remoção de óleo para diferentes $\mathrm{pH}$.

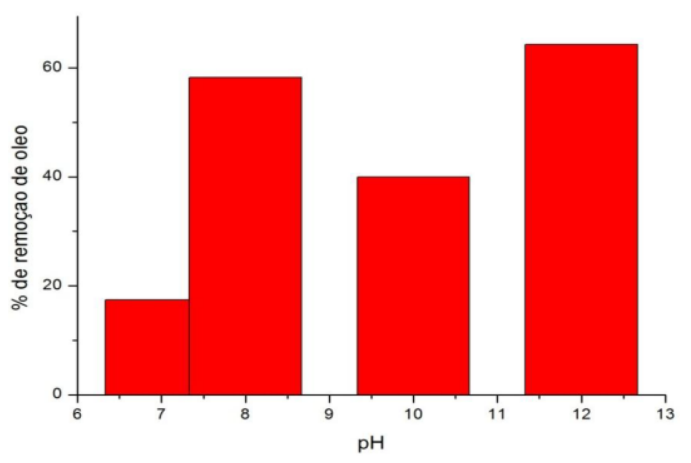

Analisando a Figura 2, pode-se perceber que $\mathrm{o} \mathrm{pH}=12$ proporcionou a maior porcentagem de remoção de óleos e graxas, igual a $73,91 \%$. A porcentagem para o $\mathrm{pH}$ ácido não foi considerado na construção da Figura 2 devido aos valores negativos.

Após a realização dos testes de $\mathrm{pH}$, estudou-se a influência do tempo de contato no processo de adsorção . A cinética de adsorção descreve a velocidade com a qual as moléculas do adsorvato são adsorvidas pelo adsorvente. Os testes foram realizados no $\mathrm{pH}$ ótimo, ou seja, em $\mathrm{pH}=12$ e em tempos variando de 10 a 360 minutos. Os testes foram realizados em duplicata e valores médios do TOG e o desvio padrão estão apresentados na Figura 3 e Tabela 3

A partir da análise de todos os resultados, observa-se que o tempo de 60 minutos no $\mathrm{pH}=12$ obteve o menor valor de TOG. 
Figura 3- Porcentagem de remoção de óleo para diferentes tempos de adsorção.

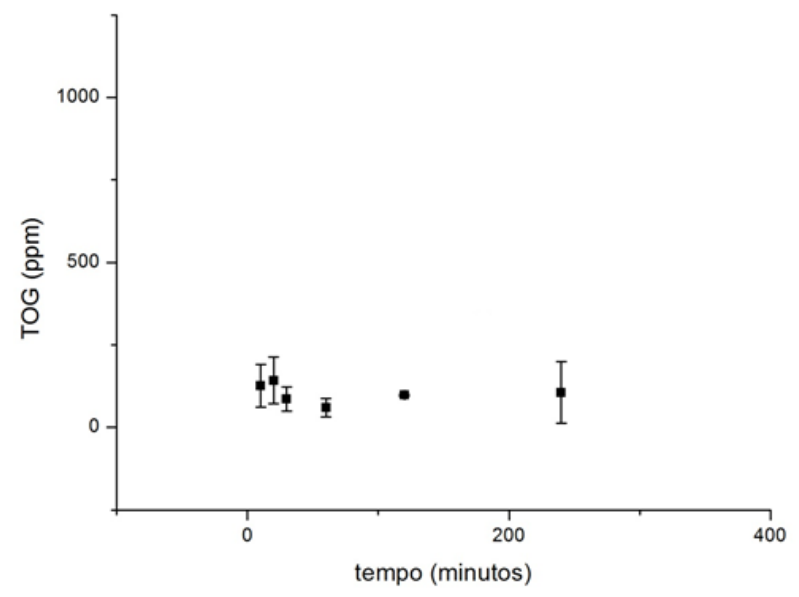

Tabela 3: Valores de remoção de TOG por tempo

\begin{tabular}{cc}
\hline $\begin{array}{c}\text { Tempo } \\
(\text { min })\end{array}$ & $\begin{array}{c}\text { Remoção de óleo } \\
(\%)\end{array}$ \\
\hline 10 & 17,83 \\
20 & 7,39 \\
30 & 43,91 \\
60 & 60,87 \\
120 & 36,09 \\
180 & $-90,43$ \\
240 & 30,87 \\
360 & $-385,22$ \\
\hline
\end{tabular}

Analisando a Figura 3 e a Tabela 3, é possível constatar que no início da operação (em tempos menores a adsorção) não foi eficiente devido ao curto tempo e os tempos maiores apresentaram elevados valores de TOG, pois pode ter dessorção do óleo previamente adsorvido. A operação de adsorção é mais rápida nos estágios iniciais, visto que no início há uma grande quantidade de sítios vazios. Com o decorrer do tempo o número de sítios vazios diminui e começa a haver a presença de forças repulsivas nas moléculas já adsorvidas, o que dificulta a adsorção nos sítios restantes (SRIVASTAVA et al, 2005). E em tempos elevados, aumenta o choque entre as moléculas o que facilita a retirada do óleo dos sítios, causando este aumento para os tempos maiores.

As características físico-químicas do óleo da amostra do efluente recolhido (como sua solubilidade, peso molecular), as caraterísticas da casca de macadâmia (como sua natureza e estrutura de poros) e as características do efluente onde o óleo está presente (como $\mathrm{pH}$ e temperatura), interferem diretamente na cinética de adsorção.

O estudo da influência da concentração de adsorvente no processo de adsorção foi realizado no $\mathrm{pH}$ ótimo e no tempo ótimo de adsorção, ou seja, no $\mathrm{pH}=12$ e no tempo de 60 minutos

Os testes foram feitos em duplicada e os resultados de TOG e de TOG médio obtidos estão apresentados na Figura 4.

Figura 4- Efeito da concentração de adsorvente na remoção de óleo do efluente. Resultados para o TOG médio.

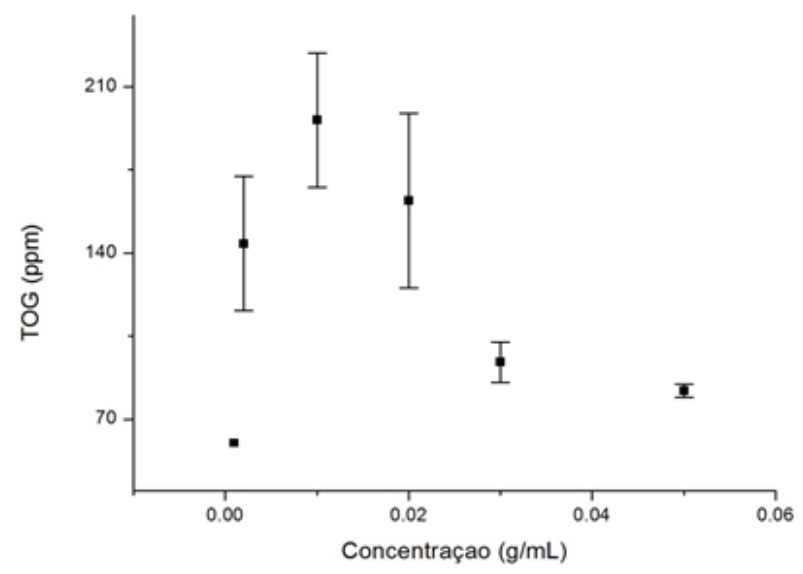

A partir da análise do gráfico pode-se concluir que os valores do TOG tendem a aumentar até uma "concentração máxima". A partir desse valor de concentração $(0,01 \mathrm{~g} / \mathrm{mL}$ de acordo com nossos resultados) os valores tendem a reduzir quanto maior a concentração. Sendo assim, a Tabela 4, apresenta a 
porcentagem média de remoção de óleo e a Figura 5 o gráfico destas porcentagens.

Tabela 4: Porcentagem de remoção de óleo do efluente em diferentes concentrações.

\begin{tabular}{cc}
\hline Concentração & \% de remoção de óleo \\
\hline $0,001 \mathrm{~g} / \mathrm{mL}$ & 60,87 \\
$0,002 \mathrm{~g} / \mathrm{mL}$ & 6,07 \\
$0,01 \mathrm{~g} / \mathrm{mL}$ & $-27,83$ \\
$0,02 \mathrm{~g} / \mathrm{mL}$ & $-5,65$ \\
$0,03 \mathrm{~g} / \mathrm{mL}$ & 38,70 \\
$0,05 \mathrm{~g} / \mathrm{mL}$ & 46,52 \\
\hline
\end{tabular}

Figura 5- Porcentagem de remoção de óleo para concentração de adsorventes em função do tempo.

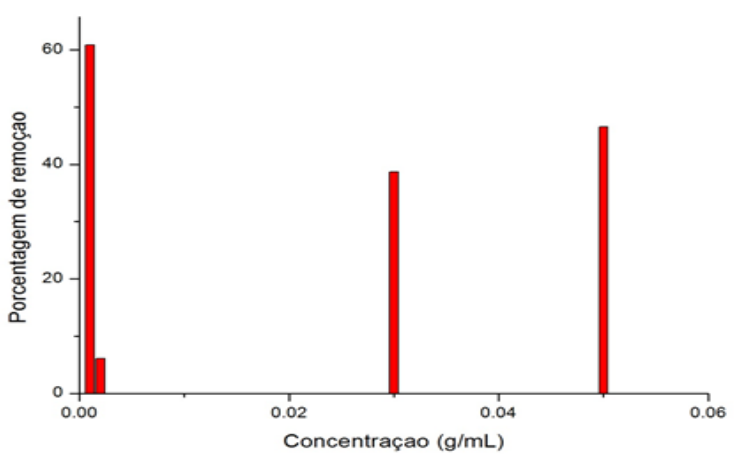

Através da análise da Figura 5, é possível concluir que a concentração ótima é a concentração de $0,001 \mathrm{~g} / \mathrm{mL}$, pois obteve a maior porcentagem de remoção de óleo. Sendo assim, este estudo comprovou os resultados obtidos pela literatura consultada; o valor ideal de concentração é de $0,001 \mathrm{~g} / \mathrm{mL}$.

Com o aumento na quantidade de material adsorvente obtém-se maior área superficial disponível para adsorção e, por consequência, maior velocidade de adsorção. No entanto, a quantidade de adsorvato removida por quantidade de adsorvente diminui, ou seja, a capacidade de adsorção diminui. Esse fato pode ser atribuído a uma diminuição nas forças de adsorção, já que se tem uma maior extensão da superfície de adsorvente para uma mesma quantidade de adsorvato (PETRONI; PIRES, 2000).
Os resultados negativos evidenciam erros experimentais, portanto não se enquadram nas explicações apresentadas acima.

Utilizando as condições ótimas já determinadas, foi feito o teste da influência da temperatura. Os testes foram feitos em duplicada e os resultados de TOG e de TOG médio obtidos estão apresentados na Tabela 5.

Tabela 5: Valores de TOG e de TOG médio para o efluente para cada temperatura.

\begin{tabular}{ccccc}
\hline Temperatura & $\begin{array}{c}\text { TOG } \\
1 \\
(\mathrm{ppm})\end{array}$ & $\begin{array}{c}\text { TOG } \\
2 \\
(\mathrm{ppm})\end{array}$ & $\begin{array}{c}\text { TOG } \\
\text { Médio } \\
(\mathrm{ppm})\end{array}$ & $\begin{array}{c}\text { Desvio } \\
\text { Padrão }\end{array}$ \\
\hline Ambiente & 212 & 220 & 216 & 5,66 \\
$40^{\circ} \mathrm{C}$ & 380 & 436 & 408 & 39,60 \\
$50^{\circ} \mathrm{C}$ & 260 & 304 & 282 & 31,11 \\
$60^{\circ} \mathrm{C}$ & 132 & 136 & 134 & 2,83 \\
$70^{\circ} \mathrm{C}$ & 340 & 240 & 290 & 70,71 \\
\hline
\end{tabular}

A Figura 6 mostra os dados de TOG médio da Tabela 7.

Figura 6- Efeito da temperatura na remoção de óleo do efluente. Resultados para o TOG médio.

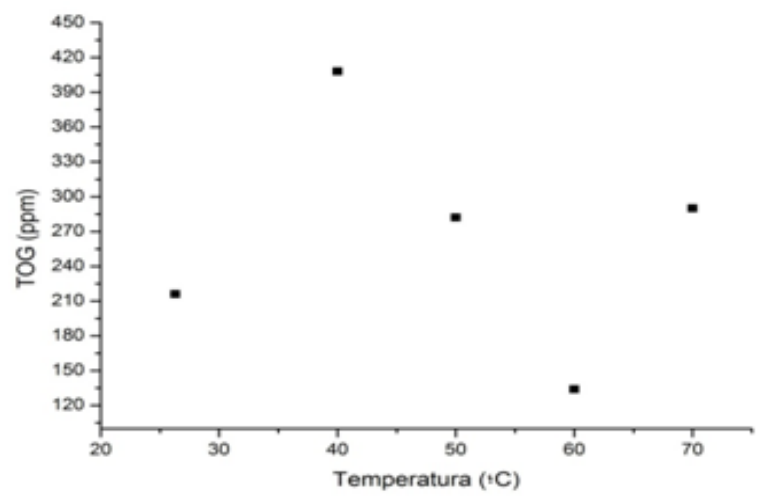

Analisando a Tabela 7 e a Figura 6, conclui-se que a temperatura de $60^{\circ} \mathrm{C}$ é a ótima, devido ao menor TOG.

A Tabela 8 apresenta a porcentagem média de remoção de óleo. Para a realização do teste de temperatura, foi utilizado um óleo bruto com o TOG Médio de 548. 
Tabela 8: Porcentagem de remoção de óleo do efluente em diferentes temperaturas.

\begin{tabular}{cc}
\hline Temperatura & \% de remoção de óleo \\
\hline Ambiente & 60,58 \\
$40^{\circ} \mathrm{C}$ & 25,55 \\
$50{ }^{\circ} \mathrm{C}$ & 48,54 \\
$60^{\circ} \mathrm{C}$ & 75,55 \\
$70{ }^{\circ} \mathrm{C}$ & 47,08 \\
\hline
\end{tabular}

Figura 7.

Utilizando a Tabela 8, construiu-se a

Figura 7- Porcentagem de remoção de óleo para as temperaturas de 26,3 (ambiente); 40; 50; 60; $70^{\circ} \mathrm{C}$.

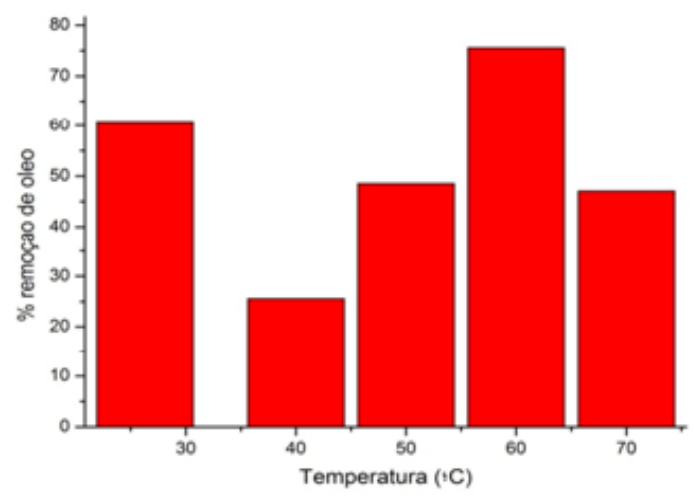

A partir da análise da Figura 7, concluise que a temperatura de $60{ }^{\circ} \mathrm{C}$ obteve a maior porcentagem de remoção, sendo assim considerada a temperatura ótima de adsorção.

Os resultados obtidos por Haussard et al (2003), quando estudaram a separação de hidrocarbonetos e lipídios da água utilizando casca de Pinus pinaster tratada, mostram que a viscosidade dos hidrocarbonetos possui forte relação com a temperatura, onde, o aumento desta, torna o composto mais "fluido" e, por isso, a acessibilidade das moléculas nos poros do bioadsorvente é facilitada, permitindo uma penetração mais profunda do óleo no material e aumentando portanto, a capacidade de adsorção. Porém, devem-se levar em consideração a tensão superficial sólido-fluido e as forças de adesão e de coesão. $\mathrm{O}$ aumento da temperatura do processo aumenta a energia cinética das moléculas, diminuindo a tensão superficial sólido-líquido e, portanto, aumentando o contato entre o adsorvente e o adsorbato. No entanto, se a temperatura for muito elevada, a vibração das moléculas será tanta que a ligação estabelecida pela adsorção se rompe, com isso, ocorrendo uma diminuição na retenção do poluente em questão.

Após a determinação do $\mathrm{pH}$, do tempo, da concentração e da temperatura ótimas, foi feito o teste para determinar a granulometria ótima, utilizando as condições anteriores. $\mathrm{O}$ TOG do teste foi feito em duplicata, utilizando um óleo bruto com TOG Médio de 1080, e os resultados estão apresentados na Tabela 9.

Tabela 9: Valores dos TOG's e dos TOG's médios para o efluente em diferentes valores de granulometria.

\begin{tabular}{lllll}
\hline Mesh & $\begin{array}{l}\text { TOG } \\
(\mathrm{ppm})\end{array}$ & $\begin{array}{l}\text { TOG 2 2 } \\
(\mathrm{ppm})\end{array}$ & $\begin{array}{l}\text { TOG } \\
\text { Médio } \\
(\mathrm{ppm})\end{array}$ & $\begin{array}{l}\text { Desvio } \\
\text { Padrão }\end{array}$ \\
\hline+10 & 376 & 364 & 370 & 8,49 \\
+14 & 592 & 368 & 480 & 158,4 \\
+20 & 272 & 312 & 292 & 28,28 \\
+24 & 552 & 532 & 542 & 14,14 \\
+28 & 624 & 588 & 606 & 25,46 \\
Fundo & 840 & 800 & 820 & 28,28 \\
\hline
\end{tabular}

A Figura 8 mostra a variação de TOG em função da granulometria do adsorvente.

Figura 8- Efeito da granulometria na remoção de óleo do efluente. 


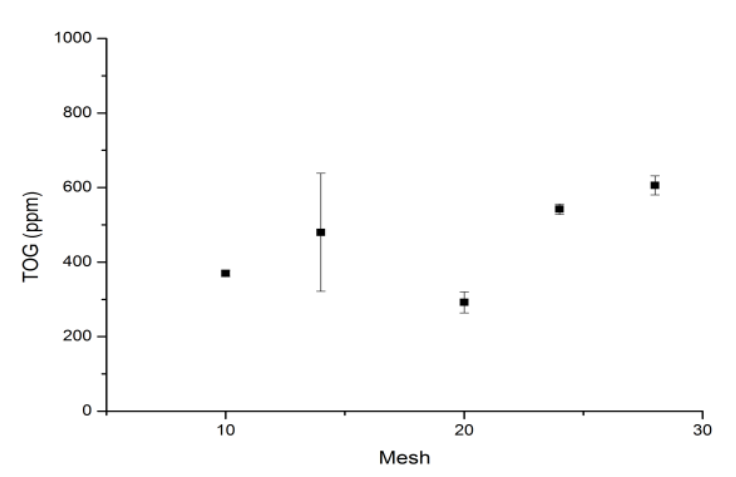

A tabela 10 apresenta as porcentagens de remoção de óleo para cada granulometria testada.

Tabela 10: Porcentagem de remoção do óleo do efluente em diferentes granulometrias.

\begin{tabular}{cc}
\hline Amostra & \% de remoção de óleo \\
\hline 10 & $65,74 \%$ \\
14 & $55,56 \%$ \\
20 & $72,96 \%$ \\
24 & $49,81 \%$ \\
28 & $43,89 \%$ \\
Fundo & $24,07 \%$ \\
\hline
\end{tabular}

Com a Tabela 10 construiu-se a Figura 9, que mostra as porcentagens de remoção de óleo para cada granulometria.

Figura 9- Porcentagem de remoção de óleo para diferentes granulometrias.

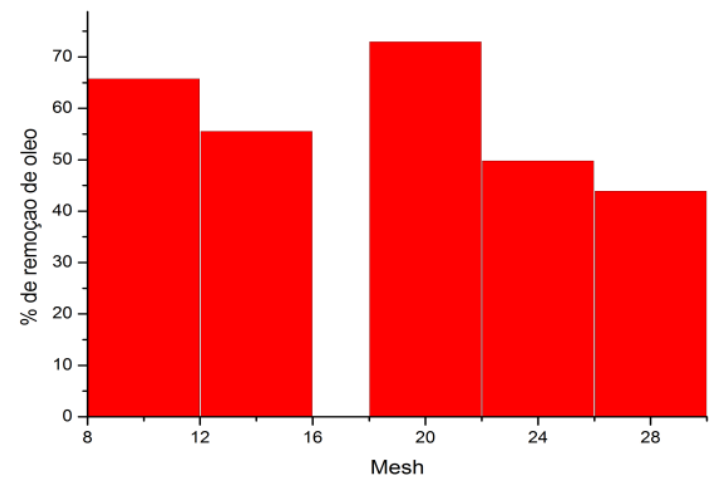

De acordo com os resultados obtidos e com as análises apresentadas, a granulometria que apresentou maior porcentagem de remoção de óleo nas condições ótimas estudadas, foi a de mesh 20 . Os resultados encontrados não seguiram uma tendência.

\section{CONCLUSÃO}

Com base nos resultados obtidos neste estudo foi possível chegar à conclusão de que a casca de macadâmia apresentou uma boa capacidade de remoção de óleo do efluente bruto, chegando até em porcentagens maiores de $70 \%$ em condições ótimas de trabalho. Porém, essa porcentagem de remoção não é suficiente, pois não atinge o valor requerido pela legislação. No entanto, a macadâmia pode ser considerada como uma técnica alternativa e complementar às existentes para o tratamento deste tipo de efluente, utilizando a mesma juntamente com outro bioadsorvente ou até mesmo com o carvão ativado.

\section{REFERÊNCIAS}

APHA, AWWA, WWEF. Standart Methods for examination of Water and wastewatwer. 22 nd ed. Washington: American Public Health Associatin; 2012, 1360 pp.

CONAMA - Conselho Nacional do Meio Ambiente - Resolução 430 de 13 de maio de 2011. Dispõe sobre as condições e padrões de lançamento de efluentes, complementa e altera a Resolução no 357, de 17 de março de 2005.

GOMIDE, R.; Operações Unitárias. $1^{\text {a }}$ Edição, São Paulo, V. 4, Cap. IV, pág. 311331, 1988.

HAUSSARD, M. et al. Separation of hydrocarbons and lipid from water using treated bark. Water Research, n. 37, p. 362374, 2003.

PETRONI, S. L. G. E PIRES, M. A. F. Adsorção de zinco e cádmio em colunas de turfa. Química Nova, 23, 477-481, 2000. 
Pollard, S. J. T.; Fowler, G. D.; Sollars. C. J.; Perry, R.. Low cost adsorbents for waste and wastewater treatment: a review. Sci. Total Environ., v.116, p.31-52, 1992. Pós graduação em Química, 2006. Dissertação de Mestrado, 73p.

RUTHVEN, D. M. Principles of Adsorption and Adsorption Process, John Wiley \& Sons, New York, 432 p., 1984.

SANTOS, S. V. Utilização de resíduos siderúrgicos como adsorventes de baixo custo no tratamento de efluentes contendo emulsões oleosas. Dissertação de Mestrado. Programa de Pós - Graduação em Saneamento, Meio Ambiente e Recursos Hídricos. Universidade Federal de Minas Gerais. Belo Horizonte, 2013.

SRIVASTAVA, V. C., SWAMY, M. M., MALL, I. D., PRASAD, B., MISHRA, I. M.;Adsorptive removal of phenol by bagasse fly ash and activated carbon: Equilibrium, kinetics and thermodynamics. Colloids and Surfaces A: Physicochem, Eng.Aspects v.272 p.89 - 104, Setembro 2005. 